\title{
Pemberitaan Masalah Rumah Tangga Selebritis sebagai Media spectacle (Guy Debord)
}

\author{
Mutia Rahmi Pratiwi \\ Universitas Dian Nuswantoro (UDINUS) Semarang
}

\begin{abstract}
Television has become an integral part of the community. Television presents a variety of diverse programs that include educational information, news and even entertainment gossip into the infotainment program. Among the various programs, infotainment now to be excellent for the television audience because many issues debated households are packed into the sensational news, ranging from gonogini property issues, differences in belief, a large family conflict, inequality of income, until the emergence of a third part which further adds chaotic household. Various household problem Infotainment packaging style will be the center of attention of the audience infotainment to continue watching the story of the conflict, like watching endless soap opera. This paper discusses the issues of households reporting celebrities as a media spectacle.
\end{abstract}

Key Words : Infotainment, Household Problems, Selebrity, Media Spectacle

\begin{abstract}
Abstraks
Televisi kini menjadi bagian tak terpisahkan dari kehidupan masyarakat. Televisi menyajikan berbagai program acara yang beragam diantaranya berisi informasi yang mendidik, pemberitaan bahkan gosip yang menjadi hiburan dalam program infotainment. Diantara berbagai program, infotainment kini menjadi "primadona" bagi penonton televisi karena memunculkan berbagai polemik persoalan rumah tangga yang dikemas menjadi berita sensasional, mulai dari persoalan harta gono gini, perbedaan keyakinan, konflik keluarga besar, ketimpangan penghasilan, hingga munculnya pihak ketiga yang semakin menambah kisruh rumah tangga. Berbagai persoalan rumah tangga ala kemasan Infotainment akan menjadi pusat perhatian para penonton infotainment untuk terus mengikuti alur cerita konflik tersebut, layaknya menonton sinetron yang tak berkesudahan. Paper ini membahas mengenai pemberitaan masalah rumah tangga selebritis sebagai media spectacle.
\end{abstract}

Kata Kunci: Infotainment, Masalah Rumah Tangga, Selebritis, Media Spectacle

\section{Pendahuluan}

Infotainment merupakan jelmaan panggung catwalk bagi para artis yang sedang berjalan dalam dunia keartisannya untuk menjaga stabilitas dan popularitas mereka. Efektiftas metode televisi dalam mengaduk-aduk emosi penonton melalui infotainment terlihat ketika infotainment menyuguhkan pro dan kontra yang sebenarnya bisa saja berubah dalam hitungan detik. Inilah yang disebut clift hanger, yang berfungsi untuk mengikat 
rasa penasaran dan emosi penonton agar selalu setia menanti perkembangan berita selanjutnya. Infotainment merupakan hasil komodifikasi atau perubahan wujud rasanan, ngerumpi, atau gosip keseharian masyarakat ke dalam media televisi. Infotainment ibarat pupuk penyubur budaya ngegosip dalam perbincangan masyarakat yang difasilitasi oleh televisi (Santosa, 2012: 3).

Berbagai hal yang berkaitan dengan selebritis menjadi komoditas layak jual dari hanya untuk hiburan penonton hingga menjadi obrolan ringan untuk menambah seru situasi ngerumpi. Beberapa hal yang menjadi sajian infotainment adalah kontribusi karya di dunia entertainment, hobi atau kegiatan selebritis sehari-hari, simbol-simbol kesejahteraan finansial yang dimiliki (mobil mewah, tas mewah, jalan-jalan ke luar negeri, dan sebagainya), bahkan perseteruan dengan pihak tertentu hingga problematika persoalan rumahtangga yang seharusnya tertutup rapat untuk di blow up di media.

Permasalahan dalam rumah tangga bukan merupakan hal yang tidak mungkin terjadi, sehingga seringkali menjadi dapur pribadi yang ditutup rapat dari orang lain, Namun apa jadinya bila persoalan rumah tangga justru dikemas menjadi layak konsumsi oleh publik? Hal inilah kini sedang mewarnai berbagai acara infotainment di televisi. Ketidakramahan persoalan rumah tangga menjadi hal yang diulang-ulang dibahas tidak hanya dalam satu acara infotainment namun menjadi trending topik di hampir semua infotainment yang tayang di televisi. Bahkan pengulangan yang terjadi tidak hanya di televisi namun juga ke majalah atau tabloid yang mengupas tuntas kehidupan selebritis. Hal ini ibarat mengasah pisau permasalahan rumah tangga hingga semakin runcing dan siap menyakiti dari berbagai sisi. Kalimat "konon, menurut orang terdekat, sumber terpercaya, pengakuan salah satu keluarga atau kerabat dekat" menjadi kalimat yang seringkali muncul untuk meyakinkan penonton akan tayangan yang disajikan infotainment adalah fakta yang sedang terjadi.

Data menunjukan bahwa sejak acara kemunculannya pertama kali hingga saat ini, infotainment terus mengalami kemajuan dalam hal kuantitas penayangannya dalam setiap minggunya. Menurut Agus Maladi Irianto, mengutip catatan Komisi Penyiaran Indonesia (KPI) Pusat sebagai berikut: Pada tahun 2002, frekuensi tayangan infotainment 24 episode setiap minggu, atau 3 episode per hari yang ditayangkan 10 stasiun televisi swasta di Tanah Air. Pada tahun 2003 meningkat menjadi empat kali lipat, menjadi 101 episode per minggu atau 14 episode per hari. Pada tahun 2004 meningkat menjadi 151 episode per minggu atau 22 episode per hari. Pada tahun 2005 meningkat menjadi 180 episode per minggu atau 26 episode per hari. Selama penelitian bulan Januari sampai dengan Agustus 2007, jumlah penayangan infotainment menjadi 210 episode per minggu atau sebesar 15 jam per hari. Dari hasil penelitian tersebut terlihat bahwa televisi telah merasuki kehidupan kita sehari-hari, dari pagi sampai malam (Edratna, (2008), Acara yang diminati Pemirsa Televisi, http://edratna.wordpress.com/2008/01/ o7/infotainment-acara-yang-diminatipemirsa-televisi/, diakses pada 23 Januari 2014).

Tingginya konsumsi masyarakat terhadap pemberitaan permasalahan rumah tangga para selebriti dapat ditunjukan dengan data peningkatan jumlah penonton infotainment pada gosip hangat yang dipoles sedemikian rupa oleh para pekerja infotainment. Data AGB 
Nielsen tahun 2010 menunjukan bahwa ketika isu mengenai video porno selebritis beredar pada awal Juni, durasi menonton Infotainment laki-laki dan perempuan dewasa bertambah. Perempuan menghabiskan lebih banyak waktu untuk menonton Infotainment daripada lakilaki. Selama minggu pertama isu tersebut muncul di sejumlah stasiun TV nasional, waktu menonton perempuan dewasa bertambah 23 menit menjadi 2 jam 9 menit, sedangkan laki-laki bertambah 13 menit menjadi 1 jam 20 menit. Namun pada saat stasiun TV mengurangi liputan atas isu tersebut di minggu berikutnya, rata-rata waktu menonton Infotainment juga menurun. Di minggu terakhir bulan Juni, waktu menonton Infotainment di kelompok perempuan dewasa berkurang 22 menit menjadi 1 jam 47 menit seminggu, sedangkan di kelompok lakilaki dewasa turun 4 menit menjadi 1 jam 15 menit seminggu. Hal ini menjadi bukti bahwa gosip hangat selalu mengundang keingintahuan yang berbuntut pada meningkatnya jumlah pemirsa, tidak hanya perempuan, tetapi juga laki-laki (Anonim, (2010),

NielsenNewsletterJun2010, www.agbnielsen.net/Uploads/.../Nielsen

\section{Nama Pasangan}

Lydia Kandou - Jamal Mirdad

Katon Bagaskara - Ira Wibowo

Titi Rajo Bintang - Wong Aksan

Venna Melinda - Ivan Fadilla

(Agus BS, (2013), Ini Dia Lima Kasus Perceraian Paling Mengejutkan Tahun Ini, http://www.tribunnews.com/ seleb/2013/11/03/ini-dia-lima-kasusperceraian-artis-indonesia-palingmengejutkan-tahun-ini, diakses pada 10 September 2014).

Berbagai pemberitaan seputar
permasalahan rumah tangga para
NewsletterJun2010-Ind.pdf, diakses pada tanggal 22 Januari 2014)

Persoalan video porno memang cukup mengagetkan masyarakat karena juga melibatkan seorang vokalis band dan kekasihnya serta seorang artis wanita yang sudah berumahtangga. Sehingga hal ini ibarat bulatan salju yang semakin melibatkan banyak pihak dan menghantarkan pada berbagai spekulasi yang menambah ruwet masalah yang terjadi. Hal ini terus saja diulang hingga pada tahun 2012, rumah tangga si artis diguncang masalah yang terus saja dihubung-hubungkan dengan kasus video porno yang menggegerkan publik tersebut. Polemik rumah tangga terus saja mengundang keingintahuan baik pihak infotainment maupun masyarakat. Di tahun 2013, persoalan rumah tangga selebritis yang berujung perceraianpun terus bertambah bahkan para selebritis yang sudah lebih dari 10 tahun juga ada yang memilih untuk berpisah. Yahoo OMG melakukan jejak pendapat mengenai empat kasus perceraian selebriti yang paling mengejutkan di tahun 2013 dan hasil polling ini dipantau oleh Tribunnews.com. Berikut ini hasil pollingnya:

$\begin{array}{lc}\text { Voters } & \text { Persen } \\ 30.746 & 68 \\ 7.394 & 16 \\ 4.072 & 9 \\ 3.131 & 7\end{array}$

selebritis terus menjadi magnet bagi para pekerja infotainment untuk mengolahnya menjadi isu atau fakta layak konsumsi bagi publik. Persoalan sensitif yang menjadi penyebab kisruh rumah tangga menjadi sajian yang dinilai mengundang peningkatan rating setiap episodenya. Artikel ini bertujuan untuk menganalisis bagaimana pemberitaan masalah rumah 
tangga selebritis yang muncul di infotainment sebagai media spectacle.

\section{Awal Maraknya Gosip Selebriti}

Awal munculnya acara gosip selebriti berada dalam konteks kondisi industri televisi di Indonesia yang tidak stabil pada tahun 1990-an. Munculnya acara gosip merupakan respon mendekati kematian industri film di tahun 1994 dan kesuksesan Festival sinetron (Indonesian television soapies festival). Industri acara gosip selebriti mulai berkembang di tahun 1997. Genre acara ini dikembangkan dari ide Ilham Bintang, yang sebelumnya bekerja sebagai seorang jurnalis. Ia menginspirasi melalui kesuksesan programnya Buletin Sinetron (BS, Soap Opera Bulletin), Buletin didukung oleh Festival Sinetron (Indonesian Soap Opera Festival) dan dimaksudkan untuk memberikan ruang bagi para artis atau seniman untuk berbicara tentang apapun yang menarik untuk mereka, ruang yang tidak tersedia bagi mereka sebelum keberadaan buletin sinetron.Menyadari potensi ketertarikan publik, Bintang dengan rumah produksinya PT.Bintang Advis Multimedia meluncurkan Cek\&Ricek yang merupakan acara gosip pertama di industri televisi Indonesia yang disiarkan oleh RCTI. Dalam sejarahnya, Bintang mencatat bahwa banyak wartawan media cetak termasuk Firman Bintang, Remy Sutansyah, Gandung Bondowoso, Syaiful Bayan, Dimas Supriyanto, Amazon, Dalimunte, dan Zoel Fauzi Lubis telah memutuskan untuk beralih ke bisnis acara gosip selebriti menggunakan media audiovisual. Untuk wartawan media cetak ini, menghasilkan gosip selebriti seperti memiliki "mainan baru". Sejak saat itu, jumlah acara gosip di televisi semakin meningkat. Gosip selebriti menunjukkan salah satu industri yang berkembang terbesar dan tercepat di Indonesia (Yulianto, 2008: 133).
Sejak tahun 2000, berita selebriti menunjukan dirinya yang populer disebut infotainment yang melampaui iklan dan sinetron yang paling berpengaruh di Indonesia. Ini merupakan genre baru yang membatasi peran perempuan dalam masyarakat Indonesia. Sebagai bentuk hiburan budaya massa genre baru produk televisi ini memiliki poin penting untuk analisis dinamika sosial dan budaya Indonesia. Infotainment telah menjadi generasi kedua sinetron Indonesia. Program Infotainment terkait dengan sinetron dalam hal karakter, produksi, audiens, dan dampaknya. Infotainment dipasarkan sebagai perpaduan informasi dan hiburan. Pemahaman umum mengenai infotainment adalah semacam "light news", merujuk pada jenis umum program media penyiaran berita, perpaduan antara berita saat ini dan program hiburan, atau program hiburan tersruktur dalam program berita. Konten Infotainment di Indonesia adalah gosip, telah menjadi konsep utama yang disebut dengan 'feminine spheres' (Williamson 1986). Format infotainment menyampaikan elemen dasar dari "low culture" dan pihak produser infotainment mempromosikan dan melindungi dari jauh dan lebih luas serta penonton didorong untuk mencari berita selebriti yang ada sementara (Yulianto, 2008: 131).

Infotainment di stasiun televisi tampil dari pagi hari hingga sore hari dengan gosip khas infotaiment yang sehingga penonton seolah merasa ketagihan untuk terus menerus menonton sajian infotainment seburuk apapun isinya bahkan dirasa menjadi hal yang lebih penting daripada permasalahan sosial di negeri ini (kemiskinan, pengangguran, korupsi, dan sebagainya). Berdasarkan pengamatan penulis, pada tahun 2014 kini hampir semua stasiun televisi swasta memiliki program acara infotainment, yaitu: 


\begin{tabular}{|l|l|}
\hline \multicolumn{1}{|c|}{ Stasiun Televisi Swasta } & \multicolumn{1}{c|}{\begin{tabular}{c}
\multicolumn{1}{c|}{ Program Acara } \\
Infotainment
\end{tabular}} \\
\hline TRANS TV & $\begin{array}{l}\text { Insert Pagi } \\
\text { Insert Siang } \\
\text { Insert Investigasi }\end{array}$ \\
\hline SCTV & Was-was \\
& Halo Selebriti \\
& Hot Shot \\
& Status Selebriti \\
\hline RCTI & Silet \\
& Go Spot \\
& Kabar-kabari \\
& Cek\&ricek \\
\hline INDOSIAR & Kiss \\
& Hot Issue \\
\hline TRANS 7 & Selebriti Pagi \\
& Selebriti Siang \\
& Selebriti On the Weekend \\
& Seleb Expose \\
\hline Global TV & Obsesi \\
& Fokus Selebriti \\
& Spot On \\
& Seleb On Cam \\
\hline MNC TV & Tuntas \\
& Pose \\
\hline
\end{tabular}

Sumber: diolah dari berbagai data

Prolematika Rumah Tangga

\section{Selebriti sebagai Media Spectacle}

Kegiatan media sebagai upaya untuk membangun hubungan yang bermakna antara program media dan realitas yang benar-benar dialami audiens, hubungan yang bermakna antara individu dan program televisi yang dipilih. Rogge dan Jensen menemukan televisi bisa menjadi bagian dari struktur keluarga, dalam arti anggota keluarga yang diandalkan untuk selalu ada sebagai sarana untuk membuat mereka tertawa atau menangis, dan untuk memberikan rasa keamanan dalam setiap perubahan waktu yang terjadi (Gauntlett dan Hill,2001: 110).
Menurut George Gernber, media massa dianggap turut memberi andil dalam memoles kenyataan sosial. Media massa dapat memberikan hiburan, goncangan batin hingga memberikan kesempatan untuk lari dari kenyataan. Menurut Goran Hedebro, media adalah pembentuk kesadaran sosial yang pada akhirnya membentuk persepsi orang terhadap dunia dan masyarakat tempat mereka hidup. Media menemukan kekuatanya yang luar biasa untuk mengawasi salah satu dari kekuatan signifikan yang menjadi pusat eksistensi kesadaran sosial : konsepsi mental yang membentuk wawasan manusia mengenai kehidupan (Ibrahim, 2011: 85-86). 
Menonton acara infotainment menjadi hiburan tersendiri bagi penontonnya pada saat keadaan pemerintahan, sosial, ekonomi, dan politik menjadi sesuatu yang "berat" untuk ditonton dan diikuti; infotanment menjadi pertunjukan yang terus dinantikan kisahkisah seru selanjutnya. Mulai dari pagi hari, acara infotainment sudah berlomba untuk menyajikan berita terupdate bahkan hingga sore hari. Permasalahan yang sedang in seolah-olah terus diulangulang agar masyarakat selalu ingat hingga akhir ceritanya nanti menjadi satu kesatuan sinetron ala infotainment. Selebriti seolah menjadi magnet untuk terus dikulik masalah-masalah pribadinya terutama berkaitan dengan kehidupan percintaan hingga masalah rumah tangga. Persoalan sensitif dapur rumah tangga justru dikemas layaknya sinetron yang menggugah emosi para penonton untuk ikut serta berkomentar bahkan menjudge siapa yang salah dan siapa yang benar.

Melalui tontonan, media mengkonstruksikan kebiasaan rutin menjadi tontonan media yang sifatnya spesial. Hal ini melibatkan dimensi estetika dan dramatisasi, terkait dengan kompetisi seperti olimpiade. Tontonan media mengacu pada peristiwa tekhnologi yang dimediasi, di mana bentuk media seperti penyiaran, media cetak, atau peristiwa proses internet dirubah dalam bentuk pertunjukan besar-besaran. Contohnya : salah satu pemberitaan yang spektakuler menjadi pemberitaan yang muncul di berbagai media ditafsirkan sebagai breaking news sehingga mendominasi pemberitan yang muncul (Allan, $2010:$ 116).

Pemberitaan apapun yang berkaitan dengan dunia selebritis dinilai sebagai hal yang sangat menarik untuk diikuti. Persoalannya tidak lagi pada sisi empati kepada seseorang yang mengalami permasalahan rumah tangga namun pada minat masyarakat untuk mengikuti kontroversi persoalan selebritis. Infotainment kini semakin berani bahkan semakin blak-blakan mempertontonkan persoalan sosial yang seharusnya menjadi privasi seseorang. Namun ketika seseorang sudah menjadi artis maka semua terkait dirinya bahkan aibnya dinilai sebagai hal yang layak dikonsumsi publik bahkan seringkali menjadi pergunjingan tak berkesudahan di masyarakat layaknya cerita sinetron yang terus berlanjut dari satu episode ke episode lainnya.

Kehidupan politik dan sosial dibentuk secara terus menerus oleh media spectacle (tontonan media). Konflik sosial dan politik semakin dimainkan dengan ditampilkan di 'layar' oleh budaya media, seperti : kasus pembunuhan sensasional, pemboman teroris, selebriti dan skandal seks serta kasus-kasus kekerasan yang terjadi pada kehidupan sehari-hari. Media culture tidak hanya membutuhkan waktu dan energi untuk terus berkembang tetapi memerlukan waktu lebih untuk membentuk fantasi, mimpi, cara berfikir dan berperilaku serta identitas (Kellner, $2003: 1)$.

Guy Debord menyajikan gagasan umum dan abstrak tentang spectacle (tontonan), yaitu: konsep yang menggambarkan media dan masyarakat konsumen, termasuk kemasan, promosi, dan menampilkan komoditas dan produksi serta dampak dari semua media. Media Spectacle (tontonan media) merupakan fenomena media culture (kultur media) yang mewujudkan nilainilai dasar kontemporer masyarakat, melayani untuk memberikan arahan bagi individu mengenai cara hidup dan dramatisasi dari kontroversi serta perjuangan, serta sebagai bentuk resolusi konflik (Kellner, 2003: 2).

Persoalan rumah tangga dalam kemasan infotainment dapat dikategorikan sebagai media spectacle. Kompleksitas permasalahan rumah 
tangga menjadi hal yang menarik untuk disajikan karena dinilai akan selalu mengundang keingintahuan penonton sebagai fans selebriti tertentu. Hal-hal yang kontroversial dan sensasional membuat khalayak terhenyak bahwa inilah realitas semu yang diciptakan oleh infotainment demi keberlangsungan hidup media. Kisah percintaan yang berakhir dengan perselingkuhan, KDRT, konflik yang disebabkan oleh orangtua dan keluarga hingga perhitungan harta gono gini dan perebutan hak asuh anak kian ramai diberitakan di media infotainment saat ini.

Dua artis dangdut yang sedang populer saat ini, yaitu Zaskia Gotik dan Ayu Ting-ting merupakan dua selebritis yang memiliki kisah percintaan yang memilukan di tahun 2013 silam. Kedua selebriti ini sama-sama mengalami kegagalan percintaan dimana Zaskia mengalami kegagalan setelah lamaran sedangkan Ayu Ting-Ting mengalami kegagalan di saat umur pernikahannya masih seumur jagung. Pemberitaan tentang kisah percintaan mereka menjadi konsumsi publik dalam kemasan acara infotaiment. Pemberitaanpun semakin "memanas" ketika ada indikasi penipuan, perselingkuhan, mengganggu rumah tangga orang, hingga melibatkan dua pihak keluarga. Hal ini seolah menjadi sasaran empuk media infotainment untuk terus mengolahnya menjadi rangkaian cerita berseri dengan dramatisasi yang menggugah emosi penonton.

Awal pemberitaan Zaskia Gotik adalah ketika tiba-tiba ia menggelar lamaran di hotel mewah dan saat itu merupakan pertama kalinya Vicky muncul di media sebagai pasangan Zaskia. Media pun gencar mempublikasikan kemewahan acara yang digelar namun ternyata ini justru awal duka kisah percintaan Zaskia karena ia tertipu oleh sosok Vicky yang selama ini diidamkannya yang ternyata sudah memiliki istri.
"...Zaskia Gotik, merasa trauma setelah mengetahui kebohongan Vicky Prasetyo, laki-laki yang melamarnya, Ahad, 1 September 2013. Zaskia Gotik telah menghabiskan kocek hingga $R p$ 340 juta untuk menggelar prosesi lamaran di Hotel Kempinski, Jakarta Ia mengaku tidak semua adalah uang hasil jerih payahnya. Ada uang Vicky juga di dalamnya. "Uang 340 juta bukan semua uang Neng," kata Zaskia ditemui saat jumpa pers di kantor Nagaswara, Menteng, Jakarta, Kamis, 5 September 2013. Saat ini Zaskia Gotik sudah menutup buku hubungannya dengan Vicky. Zaskia berterima kasih pada semua yang telah membongkar kebohongan Vicky. Ia bersyukur belum terlanjur jauh berhubungan dengan Vicky. Zaskia Gotik juga minta maaf kepada istri Vicky, Rama Nuraini. Ia benar-benar tidak tahu kalau Vicky telah menikah sah secara agama dan juga hukum. "Untuk istri Vicky, kalau Neng ada salah mohon dimaafkan, Neng mohon maaf sebesar-besarnya," tutur Zaskia Gotik sambil menitikkan air mata..."

(Nanda Hadiyanti, 2013, Pesta Tunangan Zaskia Gotik Habiskan Rp 340 Juta,

http://www.tempo.co/read/news/2013/o 9/06/219510899/Pesta-Tunangan-ZaskiaGotik-Habiskan-Rp-340-Juta, diakses pada tanggal o5 September 2014)

Selain kisah Zaskia Gotik, Kisah Ayu Ting-Ting juga menyita perhatian publik. Bagaimana tidak? Ayu dan Enji yang selama pacaran selalu tampil mesra tiba-tiba saja diduga pisah rumah setelah baru saja menikah. Keretakan hubungan pasangan ini dikarenakan tidak adanya 
kata sepakat tentang konsep resepsi yang dilaksanakan. Kasus ini semakin memanas ketika beberapa selebriti mengaku pernah menjalin hubungan dekat dengan Enji. Persoalan Ayu tingting tidak hanya berhenti sampai kisruh rumah tangganya namun juga persoalan umur bayi dalam kandungannya, proses melahirkan hingga wajah dan nama bayinya yang disembunyikan dari sorot media dan akhirnya dipubikasikan oleh Ayu dan keluarga. Ketegaran Ayu ting-ting selalu menjadi sisi yang terus ditonjolkan dalam beberapa pemberitaan sehingga penonton akan merasa ikut terbawa emosi hingga berempati. Sisi inilah yang menjadi salah satu daya pikat bagi media untuk terus memberitakan perkembangan kasus Ayu dengan mengusik sisi psikologis penonton infotainment yang didominasi oleh kaum hawa.

Proses kehamilan Ayu tingting pung terus diberitakan hingga akhirnya Ayu sempat menghilang selama hampir 2 pekan. Setelah pemberitaan yang simpang siur, 2-3 minggu kemudian Ayu Ting-Ting muncul pertama kali di acara talkshow "Buka-Bukaan" di RCTI dengan kondisi sudah melahirkan.

“...Berdasarkan data kepemirsaan $(A B C)$ Senin (2O/1), program Buka-bukaan menempati peringkat 8 dengan rating 2,7 dan share 20,6. Bisa masuk top 10 program TV paling banyak ditonton, merupakan prestasi bagi program non-primetime. Sebagai perbandingan, episode sebelumnya tayangan Kamis (16/1), Bukabukaan hanya mampu menempati posisi 43 dengan rating 1,5 dan share 11,9; Rabu (15/1) posisi 44 dengan rating 1,6 dan share $12,5 \ldots ”$

(Panditio Rayendra, (2014), Pertama Tampilkan Ayu Ting Ting Pasca
Melahirkan, Rating "Buka-bukaan” RCTI Melejit, http://www.tabloidbintang.com/ articles/film-tv-musik/ulasan/2536-

Pertama-Tampilkan-Ayu-Ting-Ting-

Pasca-Melahirkan-Rating-Buka-bukaan-

RCTI-Melejit, diakses pada tanggal 23 Januari 2014).

Tingginya rating acara "BukaBukaan" menjadi salah satu tolok ukur bagaimana tingginya antusiasme masyarakat terhadap persoalan pribadi Ayu Tingting. Tingginya rating yang diperoleh menunjukan minat masyarakat untuk menonton dan keberhasilan media untuk menjadikan Ayu komoditas utama yang menghasilkan berbagai keuntungan. Sisi seorang wanita yang teraniaya oleh tingkah laku suaminya menjadi media spectacle yang hingga kini terus ditunggu perkembangannya. Kelanjutan cerita terkait perceraian, hak asuh anak, perkembangan anak Ayu akan selalu menjadi komoditas pemberitaan infotainment dengan tujuan kapitalisme yang menjadi tujuan utama penjualan permasalahan rumah tangga para selebriti yang sedang in saat ini.

Hal paling mendasar dari spectacle dapat dipahami sebagai infiltrasi media massa, dalam media massa tertentu seperti televisi, film dan fotografi yang menawarkan bagaimana gambaran kehidupan namun pada dasarnya merupakan false images dalam kehidupan. Masyarakat tontonan mendefinisikan bahwa media berperan aktif dalam menciptakan realitas palsu, masyarakat seperti itu tidak dapat dijelaskan semata-mata dalam hubungannya dengan media. Tontonan dapat menggambarkan masyarakat secara genesis, yaitu bagaimana masyarakat spektakuler muncul dari sebelum masyarakat industrial kapitalis. Debord menempatkan ini dalam proses komodifikasi dan reifikasi seperti yang digambarkan oleh Marx dan Lukacs. Tontonan sifatnya ditentukan oleh dasar 
pengoperasian dari sistem kapitalis yang dikembangkan di masyarakat dan terbawa dalam pengalaman sosial mereka (Taylor, 2008: 113).

Bentuk komoditas "mencapai pemenuhan yang absolut dalam tontonan" dimana dunia nyata diganti dengan pilihan gambar yang lebih dari realitasnya dan menentukan dirinya sebagai keunggulan yang berwujud nyata (Debord 1977: N35), sehingga media tidak membawa namun lebih dibawa menjadi sebuah tontonan. Hal yang dikonseptualisasikan dalam tontonan adalah dapat dilihat sebagai komoditas yang dilakukan sebagai bentuk awal dari pertukaran. Debord menggunakan definisi spectacle (tontonan) untuk mendeskripsikan fenomena kultural yang unik muncul pada poin dimana uang menjadi bagian dari keseluruhan lingkungan dalam struktur kehidupan kita. Tontonan dikembangkan sebagai pelengkap uang dimana totalitas komoditas seluruhnya muncul seperti sebuah kesetaraan umum untuk apa masyarakat mendapatkannya (1977: N49 dalam Taylor, 2008: 114).

Bagi pekerja infotainment permasalahan selebriti menjadi good news yang ketika nilai jualnya tinggi maka harus segera digali lebih dalam. Bahkan pemberitaan buruk dari seorang artis juga bisa diperpanjang dengan melibatkan kerabat atau bahkan tetangga artis yang entah akurat atau tidak kemudian memberikan statement yang menjadi dasar publikasi persoalan tersebut. tidak cukup hanya dengan satu kali siaran dan persoalan publikasi selesai begitu saja. Namun diperlukan pengulangan terkait persoalan selebritis untuk mengingatkan penonton infotainment pada peristiwa lalu yang menjadi bagian cerita yang ditunggu-tunggu ending ceritanya. Disinilah media menunjukan kontribusinya dalam menyebarluaskan persoalan privasi seorang artis kepada seluruh masyarakat.

Permasalahan rumah tangga lainnya yang sempat meramaikan panggung infotainment adalah banyaknya perceraian di sepanjang tahun 2013 lalu.

“...Berikut ini daftar artis yang
memilih pernikahannya di 2013: Titi Sjuman-Wong Aksan; Tata Janeeta-Efran Fitrianto; Febby Febiola-Bruce Nicholas Deltail; Bian "D'Bagindas"-Samrotul Sa'diyah; Camelia Malik- Harry Capri; Lydia Kandou-Jamal Mirdad; Henidar Amroe- Brio Al Khoir; Rina Nose- Ridwan Feberani Anwar; Katon Bagaskara-Ira Wibowo, Venna Melinda-Ivan Fadilla; Cornelia Agatha-Sony Lalwani; Joy Tobing-Daniel Sinambela; dan Asmirandah-Jonas Rivanno..."

(Ari Kurniawan, (2013), Rumah Tangga Artis yang Berakhir Selama 2013, http://tabloidbintang.com/ articles/extra/top-list/1683-

Rumah-Tangga-Artis-yangberakhir-Selama-2013, diakses pa tanggal o5 September 2014).

Kasus perceraian para selebritis yang terjadi di tahun 2013 selalu diawali dengan desas desus yang terdengar oleh pihak tertentu dan kemudian di blow up di media. Bahkan pihak infotainment pun mendatangi pengadilan agama guna melihat siapa saja selebritis yang melayangkan gugatan cerai. Permasalahan rumah tangga yang muncul berkaitan dengan isu orang ketiga, perbedaan keyakinan, kekerasan dalam rumah tangga (KDRT), pisah ranjang, hingga kurangnya perhatian terhadap keluarga. Berbagai penyebab yang muncul terus saja dikulik oleh infotainment sehingga pemberitaan yang muncul secara terbuka menggambarkan bagaimana perpisahan dalam keluarga dapat terjadi. Hal ini tentu saja menjadi ironi tersendiri bagaimana 
rahasia keluarga menjadi konsumsi publik yang disiarkan bahkan hingga berulangulang. Dan dalam jangka waktu tertentu ketika selebriti $\mathrm{x}$ mengalami masalah kembali akan diselalu dikaitkan dengan persoalan yang pernah dialamiya di masa lalu.

Media infotainment juga seolah menjadi media publikasi atas perseteruan yang terjadi dalam rumah tangga. Contohnya pada kasus Asmirandah dan Vanno yang mempublikasikan perpindahan keyakinan salah satu pihak agar dapat berlangsung pernikahan, munculnya masalah dengan orangtua dan keluarga besar, hingga pembatalan pernikahan. Bahkan pada kasus ini sempat terjadi konflik dengan FPI karena adanya dugaan penistaan agama yang dilakukan oleh Jonas Rivanno. Pemberitaan terbaru menyebutkan bahwa keduanya sudah menikah lagi di Luar Negeri, berikut pemberitaanya:

“...Pesinetron AsmirandahZantm an (24) mengaku sudah menikah kembali dengan Jonas

Rivanno Watimena (25). Tetapi, kapan dan dimana Andah dan Vanno menikah, tidak dijelaskan."Sudah, memang sudah (menikah lagi)," kata Andah ketika datang ke Gedung Komisi Penyiaran Indonesia (KPI). Kedatangan Andah tanpa Vanno ke Gedung KPI itu untuk mengungkapkan keberatannya atas berbagai pemberitaan di tayangan 'infotainment' dan media lain yang memberitakan seputar foto berdoanya di sebuah tempat seperti gereja. Dengan nada suara yang sedikit 'tinggi', Andah menegaskan, pernikahannya dengan Vanno telah digelar di luar Indonesia. Di negara mana Andah dan Vanno menikah, tidak jelas. "Prosesnya di luar negeri," ucap Andah. "Yang jelas, masalah nikah, kami sudah menikah (lagi)," kata Asmirandah. Kala pernikahan digelar, Andah dan Vanno sudah memberitahu ke orangtua masing-masing. Andah juga mengajak Anton Zantman, ayahnya. Namun, Anton batal hadir karena ada beberapa kondisi yang tidak memungkinkannya hadir di pernikahan putrinya tersebut..."

(Heribertus Irwan Wahyu Kintoko, 2014, Asmirandah Akui Menikah Lagi Dengan Jonas Rivanno, http://www.tribunnews. com/seleb/2014/01/29/asmirandah-akuimenikah-lagi-dengan-jonas-rivanno-diluar-negeri, diakses pada tanggal o5 September 2014)

Beberapa contoh kehidupan permasalahan selebriti yang telah dibahas masuk dalam kategori 13 topik paling dibicarakan di tahun 2013 versi tabloid bintang.

“...Tahun 2013 ini ada banyak topik dalam dunia hiburan yang jadi bahan gunjingan publik dan media.Topik ini tak hanya dibicarakan selama hitungan hari, ada pula yang hitungan bulan. Nah, berbagai topik hangat yang paling diperbincangkan itu kami rangkum dalam 13 Topik Paling Dibicarakan di Tahun 2013, yaitu: Tertangkapnya Raffi Ahmad; Perseteruan Eyang Subur vs Adi Bing Slamet; Julia Perez Masuk Penjara dan Menunda Perkawinan; Kicauan Farhat Abbas; "Vickynisasi" Prasetyo; Idola Baru dari "X Factor Indonesia" Fatin Sidqiya; Goyang Cesar; Kematian Tragis Ustaz Jefri Al Buchori; Kecelakaan Maut Putra Ahmad Dhani; Drama Rumahtangga Ayu Ting Ting; Pernikahan Kontroversial Asmirandah-Jonas Rivanno; Olga Saputra Jadi Tersangka; dan Heboh Rumah 24 Miliar Nikita Mirzani..." 
(Endang Jamhari, 2013, 13 Topik Paling Dibicarakan Tahun ini, http://tabloidbintang.com/articles/extra/ top-list/1600-13-Topik-Paling-

Dibicarakan-Tahun-Ini, diakses pada 07 September 2014)

Tahun 2014 pun, permasalahan rumah tangga masih menjadi perbicangan hangat di infotainment. Di awal 2014 saja sudah muncul dua nama artis yang akan bercerai, yaitu Cut Tari, Kristy Jusung, dan Nikita Mirzani. Rumah tangga Cut Tari dan Yusuf Subrata sudah lama dikabarkan tidak harmonis terutama ketika muncul kasus video panas Cut Tari dan Ariel di tahun 2010 silam. Pemberitaanpun muncul dengan berbagai spekulasi dan mengarah pada dugaan adanya pihak ketiga yang menyebabkan perceraian ini terjadi, yaitu Kevin. Christy Jusung pun turut mengajukan gugatan cerainya di awal tahun 2014 ini. Berbagai isu pun muncul sebagai penyebab kekisruhan rumah tangga Christy dan Jay yaitu tidak harmonisnya hubungan Christy dengan anak Jay dari pernikahan sebelumnya.

Sepanjang tahun 2014 ini, terdapat pasangan selebriti lainnya yang sedang dalam proses perceraian diantaranya Farhat Abbas dan Nia Daniati; Tessa Kaunang dan Sandy Tumiwa; Marshanda dan Ben Kasyafani; serta Risty Tagor dan Rifky. Berbagai penyebab perceraian selebriti diberitakan di infotainment dengan berbagai dramatisasi yang membuat khalayak semakin penasaran untuk menonton. Penyebab perceraianpun diumbar di media walaupun sifatnya masih dugaan-dugaan yang belum dapat dipertanggungjawabkan kebenarannya. Hal ini semakin menegaskan bagaimana pemberitaan permasalahan rumah tangga selebritis dengan berbagai isu-isunya menjadi hal yang memiliki daya pikat tersendiri untuk terus diolah semakin sensasional dan kontroversial. Semakin jitu polesan dramatisasinya semakin nikmat juga untuk disajikan ke khalayak luas penonton infotainment.

Debord menyatakan "ketika dunia nyata dirubah menjadi image sederhana, maka image sederhana menjadi bentuk nyata dan motivasi yang efektif dari perilaku yang dihipnotis. The spectacle (tontonan) merupakan kecenderungan untuk melihat dunia dengan makna yang diciptakan oleh media tertentu (tidak dapat dipahami secara langsung), secara alami suatu peristiwa menjadi sebuah sentuhan yang dapat diterima masyarakat (secara masuk akal) pada zaman tertentu. Menurut pandangan Debord : hal yang abstrak, merupakan hal yang masuk akal sesuai dengan abstraksi umum masyarakat saat ini (Kellner, $2003: 2$ ).

Douglas Kellner memberikan contoh spesifik tentang tontonan media, bagaimana dibangun, diproduksi serta disiarkan. Saat ini tontonan media digunakan untuk menyampaikan berita dan informasi terutama pada tv berjaringan, media cetak dan internet untuk dijual dan dikendalikan oleh corporate media. Tontonan media merupakan bentuk berita, informasi dan peristiwa yang diproses oleh perusahaan media, negara dan kelompok politik, institusi dan individu yang memiliki kekuatan untuk mengkonstruksi sosial dan politik. Tontonan media muncul sebagai bentuk dominan yang mendefinisikan bagian dari realitas sosial dan politik yang ada pada tv kabel, satelit dan internet yang dapat mengubah segalanya (Allan, 2010 : 117 - 118).

\section{Penutup}

Media diibaratkan sebagai jendela raksasa. Dari jendela raksasa inilah para konsumen media bisa memantau dan menyaksikan perwajahan dunia di era globalisasi. Apa yang disajikan oleh media, mengkonstruk konsumennya untuk percaya sekaligus meyakini bahwa seperti 
itulah realita yang ada (Nurudin, 2010: 8). Apa yang disajikan oleh program acara infotainment menjadi satu bahasan yang terus menerus dikonsumsi oleh penonton setianya. Permasalahan-permasalahan yang muncul dalam rumah tangga para selebriti tanah air memiliki daya tarik tersendiri untuk terus dikemas dengan dramatisasi hingga tayang layaknya sinetron yang ditunggu akhir ceritanya. Permasalahan rumah tangga yang mengandung privasi seseorang di dalamnya menjadi media spectacle yang terus ditonton oleh penikmat infotainment. Salah satu tolok ukur kesuksesan media infotainment dalam mengemas persoalan rumah tangga selebritis adalah rating yang diperoleh acara "Buka-Bukaan" di RCTI saat menampilkan Ayu ting ting secara perdana setelah melahirkan putrinya dan polling terkait persoalan rumah tangga selebritis.

\section{DAFTAR PUSTAKA}

Allan, Struart. (2010). The Routledge Companion To news and Journalism. London : Routledge.

Ibrahim, Idi Subandi. (2011). Kritik Budaya Komunikasi : Budaya, Media dan Gaya Hidup dalam Proses Demokratisasi di Indonesia. Yogyakarta : Jalasutra

Gauntlett, David dan Anneta Hill. (2001). TV Living: Television, Culture, and Everyday life. Routledge : London

Kellner, Douglas. (2003). Media Spectacle. London : Routledge. $e^{-}$ book

Nurudin, (2010). Kutu-Kutu Media : Seksualitas dalam Globalisasi. Yogyakarta : Mata Padi Presindo

Santosa, Hedi Pudjo. (2012). Menelisik Liku-Liku Infotainment di Media Televisi. Yogyakarta: Gapai Asa Media Prima

Taylor, Paul A. dan Jan Ll. Harris. (2008). Critical Theories of Mass Media Then and Now. England : McGraw-Hill. e book
Yulianto, Ita Vissia. (2008). Consuming Gossip: A Re-domestication of Indonesian Women. dalam buku Popular Culture in Indonesia: Fluid identities in postauthoritarian politics. USA and Canada: Routledge

\section{Internet}

Anonim, (2010), NielsenNewsletterJun2010, www.agbnielsen.net/Uploads/.../ NielsenNewsletterJun2O1OInd.pdf, diakses pada tanggal 22 Januari 2014

Ari Kurniawan, (2013), Rumah Tangga Artis yang Berakhir Selama 2013, http://tabloidbintang.com/articles Lextra/top-list/1683-RumahTangga-Artis-yang-berakhirSelama-2013, diakses pa tanggal o5 September 2014

Agus BS, (2013), Ini Dia Lima Kasus Perceraian Paling Mengejutkan Tahun Ini, http://www.tribunnews.com/seleb L2013/11/o3/ini-dia-lima-kasusperceraian-artis-indonesia-palingmengejutkan-tahun-ini, diakses pada 10 September 2014 
Edratna, (2008), Acara yang diminati Pemirsa Televisi, http://edratna.wordpress.com/20 o8/01/o7/infotainment-acarayang-diminati-pemirsa-televisi/, diakses pada 23 Januari 2014

Endang Jamhari, 2013, 13 Topik Paling Dibicarakan Tahun ini, http://tabloidbintang.com/articles Lextra/top-list/1600-13-TopikPaling-Dibicarakan-Tahun-Ini, diakses pada 07 September 2014

Heribertus Irwan Wahyu Kintoko, 2014, Asmirandah Akui Menikah Lagi Dengan Jonas Rivanno, http://www.tribunnews.com/seleb 2014/01/29/asmirandah-akuimenikah-lagi-dengan-jonasrivanno-di-luar-negeri, diakses pada tanggal o5 September 2014
Panditio Rayendra, (2014), Pertama Tampilkan Ayu Ting Ting Pasca Melahirkan, Rating "Buka-bukaan" RCTI Melejit, http://www.tabloidbintang.com/ar ticles/film-tv-musik/ulasan/2536Pertama-Tampilkan-Ayu-TingTing-Pasca-Melahirkan-RatingBuka-bukaan-RCTI-Melejit, diakses pada tanggal 23 Januari 2014

Nanda Hadiyanti, 2013, Pesta Tunangan Zaskia Gotik Habiskan Rp 340 Juta, http://www.tempo.co/read/news/ 2013/09/06/219510899/PestaTunangan-Zaskia-Gotik-HabiskanRp-340-Juta, diakses pada tanggal o5 September 2014 
Jurnal komunikasi, Volume 9, Nomor 1, Oktober 2014 